\title{
Phosphorylation of GSK-3 $\beta$ by cGMP-dependent protein kinase II promotes hypertrophic differentiation of murine chondrocytes
}

\author{
Yosuke Kawasaki,1 Fumitaka Kugimiya,, ${ }^{1}$ Hirotaka Chikuda, ${ }^{1}$ Satoru Kamekura, ${ }^{1}$ Toshiyuki Ikeda, ${ }^{1}$ \\ Naohiro Kawamura, ${ }^{1}$ Taku Saito, ${ }^{1}$ Yusuke Shinoda, ${ }^{1}$ Akiro Higashikawa, ${ }^{1}$ Fumiko Yano, ${ }^{1}$ \\ Toru Ogasawara, ${ }^{1}$ Naoshi Ogata, ${ }^{1}$ Kazuto Hoshi,1 Franz Hofmann, ${ }^{2}$ James R. Woodgett, ${ }^{3}$ \\ Kozo Nakamura, ${ }^{1}$ Ung-il Chung, ${ }^{1}$ and Hiroshi Kawaguchi'
}

${ }^{1}$ Sensory and Motor System Medicine, Faculty of Medicine, University of Tokyo, Tokyo, Japan. ${ }^{2}$ Institut für Pharmakologie und Toxikologie, Technische Universität München, Munich, Germany. ${ }^{3}$ Samuel Lunenfeld Research Institute, Toronto, Ontario, Canada.

\begin{abstract}
cGMP-dependent protein kinase II (cGKII; encoded by PRKG2) is a serine/threonine kinase that is critical for skeletal growth in mammals; in mice, cGKII deficiency results in dwarfism. Using radiographic analysis, we determined that this growth defect was a consequence of an elongated growth plate and impaired chondrocyte hypertrophy. To investigate the mechanism of cGKII-mediated chondrocyte hypertrophy, we performed a kinase substrate array and identified glycogen synthase kinase- $3 \beta$ (GSK-3 $\beta$; encoded by Gsk $3 b$ ) as a principal phosphorylation target of cGKII. In cultured mouse chondrocytes, phosphorylation-mediated inhibition of GSK-3 $\beta$ was associated with enhanced hypertrophic differentiation. Furthermore, cGKII induction of chondrocyte hypertrophy was suppressed by cotransfection with a phosphorylation-deficient mutant of GSK-3 $\beta$. Analyses of mice with compound deficiencies in both protein kinases $\left(\mathrm{Prkg}^{-/-} \mathrm{Gsk} 3 \mathrm{~b}^{+/-}\right)$demonstrated that the growth retardation and elongated growth plate associated with cGKII deficiency were partially rescued by haploinsufficiency of Gsk3b. We found that $\beta$-catenin levels decreased in Prkg $2^{-/}$mice, while overexpression of cGKII increased the accumulation and transactivation function of $\beta$-catenin in mouse chondroprogenitor ATDC5 cells. This effect was blocked by coexpression of phosphorylation-deficient GSK-3 3 . These data indicate that hypertrophic differentiation of growth plate chondrocytes during skeletal growth is promoted by phosphorylation and inactivation of GSK-3 $\beta$ by cGKII.
\end{abstract}

\section{Introduction}

Skeletal growth is achieved by endochondral ossification in the growth plate cartilage, with orderly columnar arrays of resting, proliferative, and hypertrophic zones of chondrocytes. During the process, chondrocytes undergo proliferation, hypertrophic differentiation, and apoptosis, each of which is regulated by distinct molecular signaling systems (1). Among them, C-type natriuretic peptide (CNP; encoded by Nppc), a humoral factor that can regulate a variety of homeostatic processes by binding the membrane-bound guanylyl cyclase-coupled receptor B (GC-B; encoded by $N p r 2$ ), has been shown to play important roles in skeletal growth, because mice deficient in either gene exhibit impaired skeletal growth $(2,3)$. Loss-of-function mutations in Npr2 also show dwarfism in patients known as acromesomelic dysplasia, type Maroteaux (4), demonstrating the importance of CNP/GC-B

Nonstandard abbreviations used: ALP, alkaline phosphatase; Bad, BCL2-antagonist of cell death; cdc25, cell division cycle 25 homolog; cGK, cGMP-dependent protein kinase; cGKII- $\Delta$ kinase, truncated cGKII protein that lacks the kinase domain; CNP, C-type natriuretic peptide; COL10, type X collagen; GC-B, guanylyl cyclase-coupled

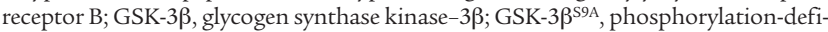
cient mutant of GSK-3 $\beta$ with a serine-to-alanine substitution; PLK, polo-like kinase; p90RSK, 90-kDa ribosomal protein S6 kinase; PTH, parathyroid hormone; PTHrP, parathyroid hormone-related protein; TCF, T cell factor; VASP, vasodilator-stimulated phosphoprotein

Conflict of interest: The authors have declared that no conflict of interest exists. Citation for this article: J. Clin. Invest. 118:2506-2515 (2008). doi:10.1172/JCI35243. signaling in the skeletal growth of humans as well. This signaling causes the intracellular accumulation of cGMP, which then activates cGMP-dependent protein kinases (cGKs) (5). In mammalian cells, there are 2 cGK isoforms, cGKI and cGKII (encoded by Prkg1 and Prkg2, respectively), which show distinct distributions and functions $(6,7)$. Although both are expressed in growth plate cartilage, Prkg $^{-/-}$mice show postnatal dwarfism with about $20 \%-30 \%$ reduction in the length of limbs and trunk (6), while Prkg1 $1^{-1}$ mice show a normal skeleton (8), indicating that only cGKII is indispensable for skeletal growth.

cGKII is a membrane-bound serine/threonine kinase with a cGMP-binding domain and a catalytic domain in the $\mathrm{C}$ terminus (7). In addition to growth retardation resulting from cGKII deficiency in mice, our previous positional cloning analysis identified a deletion in Prkg2, the rat gene encoding cGKII, in the Komeda miniature rat Ishikawa (KMI), a naturally occurring mutant rat, which also exhibited dwarfism with $20 \%-30 \%$ shorter long bones and vertebrae (9). The deletion resulted in a frame shift and a premature stop codon, predicting a truncated cGKII protein that lacks the kinase domain (cGKII- $\Delta$ kinase). KMI rats show an elongated growth plate, whose height is about 2.5 -fold that of WT littermates. This is caused by the existence of an abnormal intermediate layer between the proliferative and hypertrophic zones with accumulation of few proliferative or hypertrophic chondrocytes, which indicates that the kinase activity of cGKII is necessary for 

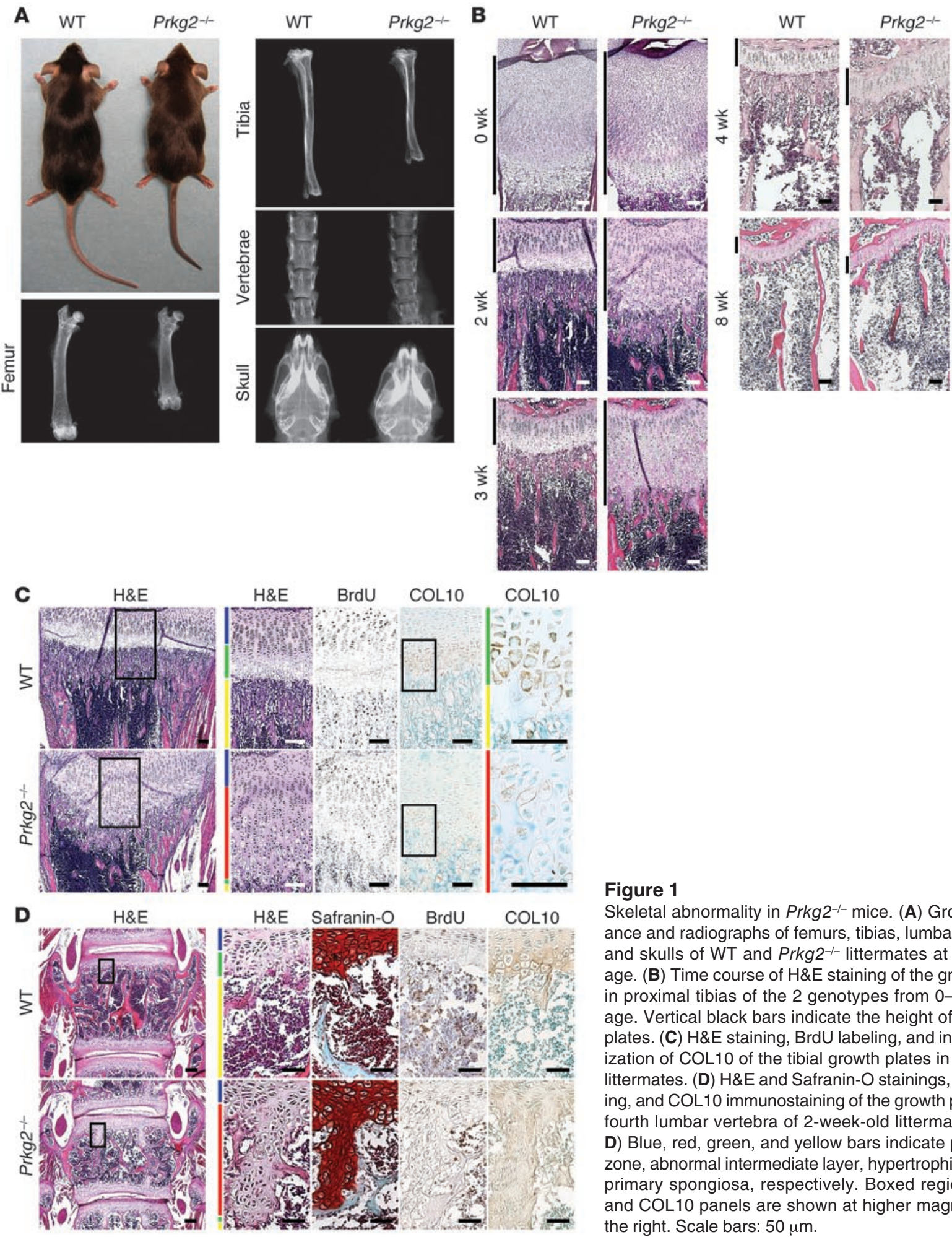

\section{Figure 1}

Skeletal abnormality in $\mathrm{Prkg}^{-/-}$mice. (A) Gross appearance and radiographs of femurs, tibias, lumbar vertebrae, and skulls of WT and Prkg2 ${ }^{-/-}$littermates at 8 weeks of age. (B) Time course of H\&E staining of the growth plates in proximal tibias of the 2 genotypes from $0-8$ weeks of age. Vertical black bars indicate the height of the growth plates. (C) H\&E staining, BrdU labeling, and in situ hybridization of COL10 of the tibial growth plates in 2-week-old littermates. (D) H\&E and Safranin-O stainings, BrdU labeling, and COL10 immunostaining of the growth plates in the fourth lumbar vertebra of 2-week-old littermates. (C and D) Blue, red, green, and yellow bars indicate proliferative zone, abnormal intermediate layer, hypertrophic zone, and primary spongiosa, respectively. Boxed regions in $\mathrm{H} \& \mathrm{E}$ and COL10 panels are shown at higher magnification to the right. Scale bars: $50 \mu \mathrm{m}$. hypertrophic differentiation of growth plate chondrocytes (9). To investigate the mechanism underlying cGKII kinase activity in chondrocyte hypertrophy, in the present study we performed a screen of its potential phosphorylation targets and identified glycogen synthase kinase- $3 \beta$ (GSK-3 $\beta$; encoded by Gsk3b) as a significant phosphorylation target of cGKII. Because the phosphory- lation of GSK-3 $\beta$ at Ser9 is known to cause its inactivation (10), we further examined the functional involvement of GSK-3 $\beta$ in the cGKII-induced hypertrophic differentiation of chondrocytes and investigated the underlying mechanism. Our results demonstrated that cGKII promotes chondrocyte hypertrophy and skeletal growth through phosphorylation and inactivation of GSK-3 $\beta$. 
A
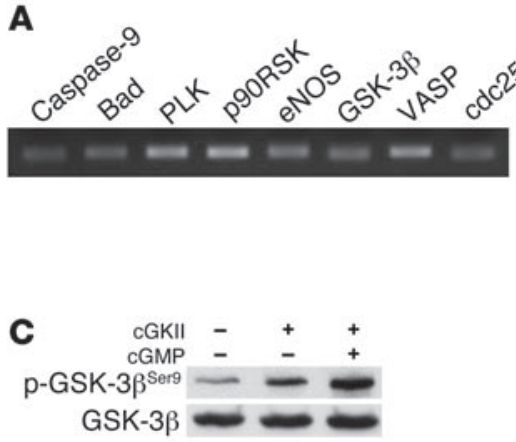

$\mathbf{E}$

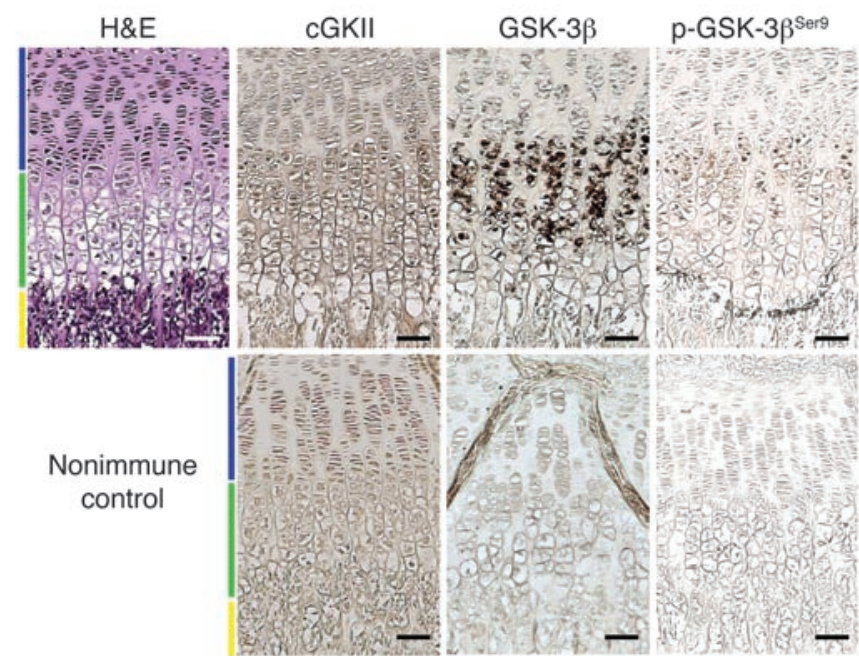

B
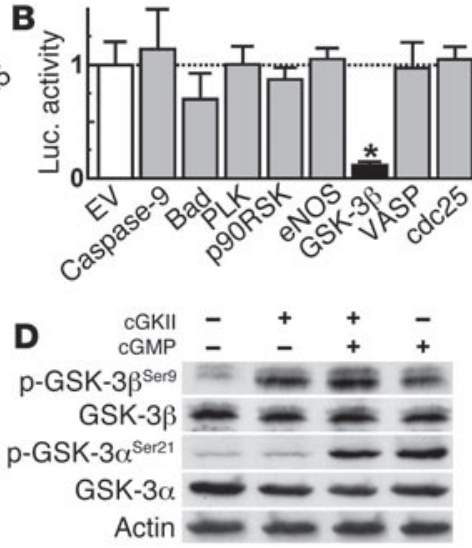

Actin

\section{Figure 2}

Identification of GSK-3 $\beta$ as a principal phosphorylation target of cGKII during chondrocyte hypertrophy. (A) RTPCR of 8 candidate genes that were identified by the serine/threonine kinase substrate array (Supplemental Table 1) in cultured ATDC5 cells in the prehypertrophic or hypertrophic differentiation stage. (B) COL10 promoter activity, as assessed by transfection of the 8 candidate genes or the empty vector (EV) in $\mathrm{HuH}-7$ cells with the luciferase reporter gene construct containing a cloned $4.5-\mathrm{kb}$ promoter fragment of COL10. Data are mean \pm SD fold change relative to empty vector. ${ }^{*} P<0.01$ versus control. (C) In vitro kinase assay of the phosphorylation of recombinant GSK-3 $\beta$ at Ser9 by recombinant cGKII with or without cGMP. Proteins were incubated in the presence of ATP, and the reaction products were analyzed by IB using the same antibody to Ser9-phosphorylated GSK-3 $\beta$ $\left(p-G S K-3 \beta^{\text {Ser }}\right)$ as that used in Supplemental Table 1. (D) Phosphorylation of endogenous GSK-3 $\beta$ at Ser9 and GSK-3 $\alpha$ at Ser21 by cGKII with or without cGMP in ATDC5 cells. Whole-cell lysates were incubated with recombinant cGKII or cGMP in the presence of ATP, and the reaction products were analyzed as in C. (E) Localization of cGKII, total GSK-3 $\beta$, and Ser9-phosphorylated GSK-3 $\beta$, as assessed by immunohistochemistry in the growth plate of proximal tibia in a 2-week-old mouse. Specific stainings were confirmed by immunohistochemistry by respective nonimmune serums (nonimmune control). Blue, green, and yellow bars indicate proliferative zone, hypertrophic zone, and primary spongiosa, respectively. Scale bars: 50 um.

\section{Results}

Growth plate abnormality in Prkg2 $2^{-/-}$mice. Prkg2 $2^{-/-}$mice showed postnatal dwarfism with short limbs and trunk compared with WT littermates (Figure 1A), as previously reported (6). Radiographic analysis at 8 weeks of age revealed that the lengths of femur, tibia, and vertebra, which are known to be primarily formed through endochondral ossification, were shorter in Prkg $2^{-/-}$mice. The longitudinal length of the Prkg2-/- skull was also shorter, while the width was comparable to WT. This finding is probably attributable to 2 types of the skull growth via endochondral ossification and intramembranous ossification (11), although this needs to be further investigated. The time course of histological observation of the tibial growth plate revealed that the height was greater in Prkg2-/- than WT mice from 2 to 4 weeks after birth but was restored to a level comparable to that of WT mice by 8 weeks of age (Figure 1B). As previously observed in KMI rats (9), growth plate elongation during these ages was caused by an abnormal intermediate layer between the proliferative and hypertrophic zones, with accumulation of few proliferative or hypertrophic chondrocytes, as determined by BrdU uptake and expression of type X collagen (COL10), respectively (Figure 1C). The growth plate of the Prkg2 $2^{-/-}$vertebral bones also contained the abnormal intermediate layer, which was intermittently focal in the elongated growth plate (Figure 1D). These results indicate that cGKII is necessary for hypertrophic differentiation of growth plate chondrocytes during endochondral ossification for longitudinal growth of limbs and trunk not only in rats, but also in mice.

Phosphorylation targets of cGKII in chondrocyte hypertrophy. To investigate the mechanism underlying cGKII activity in hypertrophic differentiation of chondrocytes, we performed a screen of its phosphorylation targets by in vitro kinase assay using a serine/threonine kinase substrate array. From 87 candidate peptides containing serine/threonine phosphorylation sites, we identified 8 substrates that were most strongly phosphorylated by cGKII: caspase-9, BCL2antagonist of cell death (Bad), polo-like kinase (PLK), 90-kDa ribosomal protein S6 kinase (p90RSK), eNOS, GSK-3 $\beta$, vasodilator-stimulated phosphoprotein (VASP), and cell division cycle 25 homolog (cdc25) (Supplemental Table 1; supplemental material available online with this article; doi:10.1172/JCI35243DS1). All of these molecules were confirmed to be expressed in mouse chondrogenic ATDC5 cells in the prehypertrophic or hypertrophic differentiation stage (Figure 2A). However, a luciferase reporter assay revealed that GSK-3 $\beta$ markedly suppressed COL10 promoter activity, while none of the other candidates had a significant effect (Figure $2 \mathrm{~B}$ ). These data suggest that GSK-3 $\beta$ might be functionally involved in chondrocyte hypertrophy, although involvement of the other factors cannot be ruled out. Direct phosphorylation of recombinant GSK-3 $\beta$ at Ser9, the crucial site for inactivation of GSK-3 $\beta$ (10), by recombinant cGKII protein was confirmed by in vitro kinase assay using the same antibody as the screening array above, and the phos- 

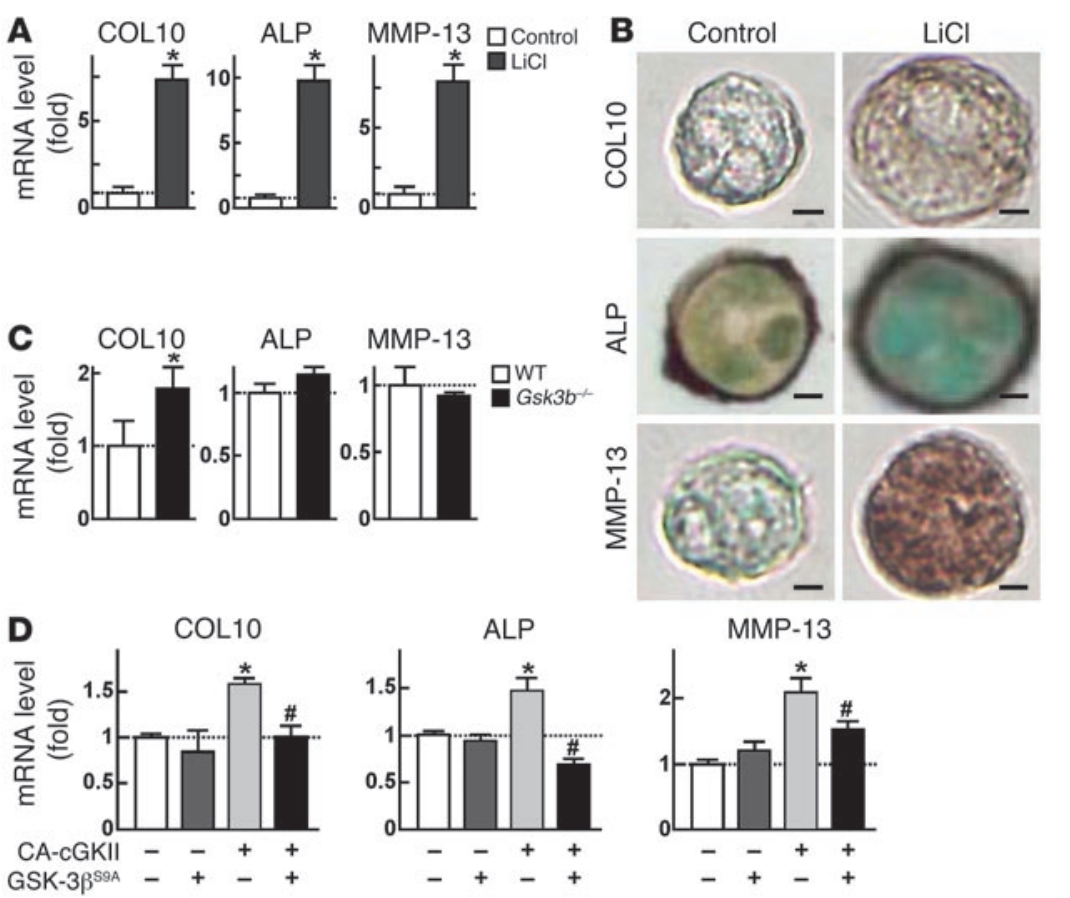

MMP-13

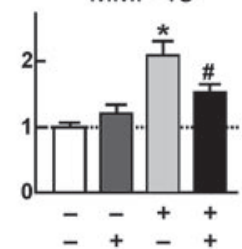

\section{Figure 3}

Regulation of chondrocyte hypertrophy by GSK-3 $\beta$. (A) Effects of $\mathrm{LiCl}$ on mRNA levels of the hypertrophic markers COL10, ALP, and MMP-13, as assessed by real-time RT-PCR in ATDC5 cells cultured in 3-dimensional alginate beads. (B) Effects of $\mathrm{LiCl}$ on the hypertrophic markers, as assessed by immunocytochemistry in primary costal chondrocytes cultured in 3-dimensional alginate beads. For morphological comparison, sections of the representative colonies containing 4 cells were selected. Scale bars: $10 \mu \mathrm{m}$. (C) mRNA levels of the hypertrophic markers, as assessed by real-time RT-PCR in cultured costal chondrocytes from WT and $G s k 3 b^{+/-}$mice. (D) mRNA levels of the hypertrophic markers in stable lines of ATDC5 cells retrovirally transfected with the constitutively active form of cGKII (CA-cGKII), GSK-3 $\beta^{S 9 A}$, or the control GFP (-). Data are mean \pm SD of the relative amount compared with control or WT. ${ }^{*} P<0.01$ versus control or WT. ${ }^{\#} P<0.01$ versus constitutively active cGKII alone. phorylation was enhanced by the addition of cGMP (Figure 2C). Furthermore, endogenous GSK-3 $\beta$ in cell lysates of ATDC 5 cells was phosphorylated at Ser9 by recombinant cGKII protein, which was further enhanced by the addition of cGMP. On the other hand, GSK-3 $\alpha$, the closely related isoform of GSK-3 $\beta$, was not phosphorylated by cGKII, nor were protein levels of GSK-3 $\beta$ and GSK-3 $\alpha$ altered by cGKII or cGMP (Figure 2D). Immunohistochemistry revealed that cGKII, total GSK-3 $\beta$, and Ser9-phosphorylated GSK-3 $\beta$ were colocalized in prehypertrophic chondrocytes of the growth plate, implicating the interaction of these molecules in vivo as well (Figure $2 \mathrm{E})$. Compared with the respective nonimmune controls, the localization of Ser9-phosphorylated GSK-3 $\beta$ appeared to be restricted to those cells that also produced cGKII, whereas total GSK-3 $\beta$ was more broadly distributed, which supports the notion that cGKII is an important regulator of GSK-3 $\beta$ phosphorylation.

Regulation of chondrocyte bypertropby by GSK-3 $\beta$. In the 3-dimensional cultures of ATDC5 cells and primary costal chondrocytes in alginate beads, $\mathrm{LiCl}$, a selective inhibitor of GSK-3 $\beta$, stimulated the expression of chondrocyte hypertrophic differentiation markers COL10, alkaline phosphatase (ALP), and MMP-13 and induced morphological hypertrophy of the cells (Figure 3, A and B). COL10 expression also increased in cultured primary costal chondrocytes from $\mathrm{Gsk} 3 b^{+/-}$mice compared with WT chondrocytes, while ALP and MMP-13 levels were comparable between the genotypes (Figure $3 \mathrm{C}$ ). Introduction of a constitutively active allele of cGKII into ATDC5 cells stimulated expression of hypertrophic markers, and this was attenuated by the cointroduction of a phosphorylationdeficient mutant of GSK-3 $\beta$ with a serine-to-alanine substitution (GSK-3 $\beta^{\mathrm{S9A}}$ ), which is known to have constitutive activity (Figure 3D). These data demonstrated that Ser9 phosphorylation of GSK-3 $\beta$ is necessary for the induction of chondrocyte hypertrophy by cGKII. The GSK-3 $\beta^{\mathrm{S} 9 \mathrm{~A}}$ introduction alone altered none of the 3 markers (Figure 3D), which indicates that an endogenous GSK-3 $\beta$ level was sufficient for the suppression of chondrocyte hypertrophy in this culture system.
Mechanism underlying cGKII/GSK-3ß signaling in chondrocyte bypertrophy. We further examined the molecular mechanism whereby GSK-3 $\beta$ phosphorylation by cGKII regulates hypertrophic differentiation of chondrocytes. Because GSK-3 $\beta$ is known to be a negative regulator of $\beta$-catenin through its phosphorylation and degradation (10), we compared the localization of $\beta$-catenin, Ser9-phosphorylated GSK-3 $\beta$, and total GSK-3 $\beta$ in the growth plates of WT and Prkg2-/- littermates. In the WT growth plate, $\beta$-catenin as well as both GSK-3 $\beta$ proteins were localized mainly in the cytoplasm of prehypertrophic chondrocytes (Figure 4A). cGKII deficiency caused similar decreases in $\beta$-catenin and Ser9phosphorylated GSK-3 $\beta$ levels with little effect on the total GSK-3 $\beta$ level in the abnormal intermediate layer. In cultured ATDC5 cells, cGKII induced cytosolic accumulation of $\beta$-catenin after stimulation by 8 -bromo-cGMP, while cGKII- $\Delta$ kinase had a minimal effect (Figure 4B). Overexpression of constitutively active cGKII enhanced the promoter activity of the $\beta$-catenin target $\mathrm{T}$ cell factor (TCF), which was markedly suppressed by cotransfection of GSK-3 $\beta^{\mathrm{S} 9 \mathrm{~A}}$ (Figure 4C). Again, GSK-3 $\beta^{\mathrm{S9A}}$ alone did not have an effect, which indicates that an endogenous GSK- $3 \beta$ level is sufficient for $\beta$-catenin suppression. We next examined the involvement of a scaffolding peptide, Axin, which is known to associate with GSK-3 $\beta$ and promotes effective phosphorylation and degradation of $\beta$-catenin under conditions of Wnt stimulation (10). IP/IB analysis using HEK293 cells transfected with Myc-tagged Axin and cGKII revealed that cGKII formed a complex with Axin and phosphorylated GSK-3 $\beta$ not only in the whole-cell lysates, but also in the IP with Axin, suggesting some interaction between Ser9 phosphorylation and coupling with Axin in regulation of GSK-3 $\beta$ by cGKII (Figure 4D).

In our previous study, we showed that cGKII caused attenuation of Sox9 transcriptional function through inhibition of nuclear entry (9). Because Sox9 is known not only to induce chondrogenic differentiation of mesenchymal cells, but also to prevent hypertrophic differentiation of chondrocytes (12), this may contribute 


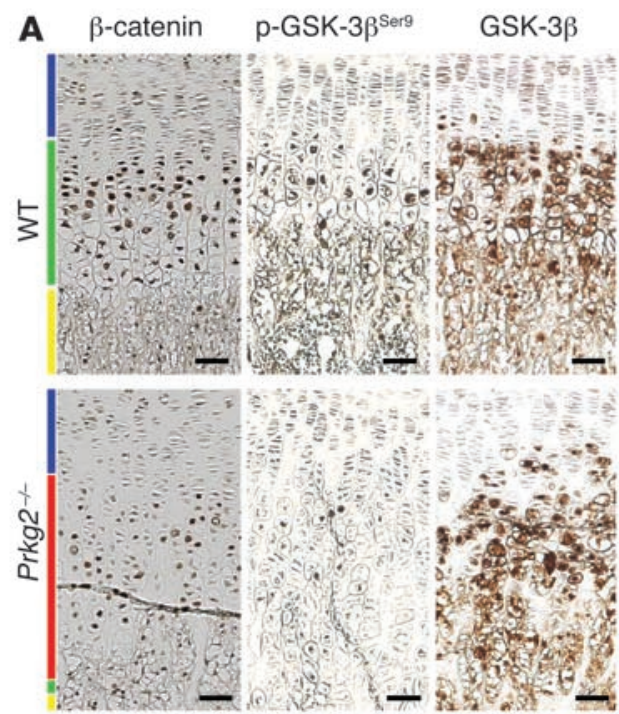

B
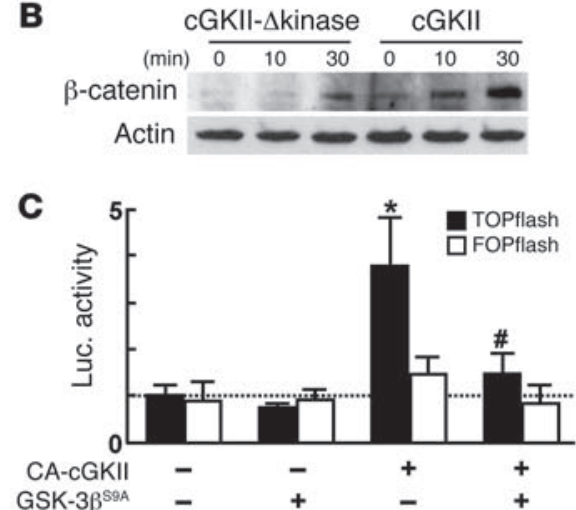

D

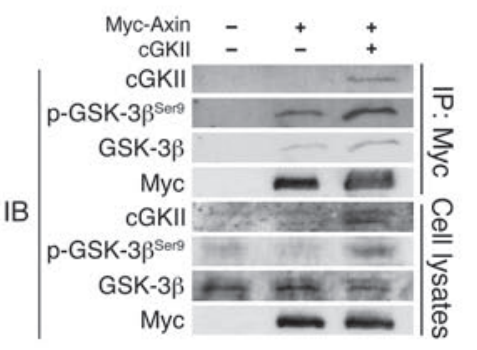

to the mechanism whereby cGKII promotes chondrocyte hypertrophy. However, inhibition of Sox9 nuclear entry by cGKII was independent of phosphorylation of Sox 9 itself, because cGKII inhibited not only the nuclear entry of the WT Sox9, but also that of the phosphorylation-deficient Sox 9 mutants with serineto-alanine substitutions at putative phosphorylation sites Ser64 and Ser181 (Figure 5A), which suggests that other phosphorylation targets of cGKII are important. We therefore examined the involvement of GSK-3 $\beta$ phosphorylation in the inhibition of Sox9 nuclear entry by cGKII. Neither addition of the GSK-3 $\beta$ inhibitor $\mathrm{LiCl}$ nor overexpression of GSK-3 $\beta^{59 \mathrm{~A}}$ altered cGKII-dependent inhibition of Sox9 nuclear entry, which indicates that the inhibitory effect of cGKII was independent of GSK-3 $\beta$ phosphorylation by cGKII (Figure 5B).

We next assessed involvement of other putative signaling systems in cGKII action on chondrocyte hypertrophy. Although

\section{Figure 4}

Mechanism underlying cGKII/GSK-3 $\beta$ signaling in chondrocyte hypertrophy. (A) Localization of $\beta$-catenin, Ser9-phosphorylated GSK-3 $\beta$, and total GSK-3 $\beta$, as assessed by immunohistochemistry in the growth plates of the proximal tibias of WT and $\mathrm{Prkg}^{-/-}$mice at 2 weeks of age. Blue, red, green, and yellow bars indicate proliferative zone, abnormal intermediate layer, hypertrophic zone, and primary spongiosa, respectively. Scale bars: $50 \mu \mathrm{m}$. (B) Time course of $\beta$-catenin protein level after stimulation by 8 -bromo-cGMP, as assessed by IB in the cytosolic fraction of ATDC5 cells with retroviral introduction of cGKII or cGKII- $\Delta$ kinase. (C) Promoter activity of the $\beta$-catenin target TCF, as assessed by luciferase (Luc) assay using TOPflash and FOPflash reporter plasmids in HEK293 cells transfected with constitutively active cGKII, GSK-3 $\beta^{\mathrm{S9A}}$, or the control GFP $(-)$. Data are mean \pm SD fold change compared with control $(-/-)$. ${ }^{*} P<0.01$ versus control. $\# P<0.01$ versus constitutively active cGKII alone. (D) Physical association of cGKII and GSK-3 $\beta$ with Axin by IP/IB analysis. HEK293 cells were transfected with Myc-tagged Axin (Myc-Axin) and/or cGKII, and an aliquot of the cell lysates underwent IP with the high-affinity antic-Myc antibody-coupled agarose as described in Methods. The IP (Myc) or the whole-cell lysates underwent IB with an antibody to cGKII, Ser9-phosphorylated GSK-3 $\beta$, GSK-3 $\beta$, or Myc.

Runx2 has previously been shown to be an important transcription factor that induces hypertrophic differentiation of chondrocytes (13), its expression was visible in the abnormal intermediate layer of the $\mathrm{Prkg}^{-{ }^{--}}$growth plate (Supplemental Figure 1A). In addition, neither the mRNA level nor the subcellular localization of Runx2 was altered by cGKII overexpression in cultured ATDC5 cells (Supplemental Figure 1, B and C).

FGF signaling has also been shown to be important for chondrocyte differentiation and endochondral ossification in mice and humans (14). Considering that targeted overexpression of CNP in chondrocytes counteracts dwarfism in a mouse model of achondroplasia with activated FGF receptor 3 (15) and that the mutant mice exhibit an elongated growth plate similar to that of Prkg2 $2^{-/}$mice (16), there might be cross-talk between cGKII and FGF signaling. Because FGF signaling stimulates MAPK or STAT-1 signaling pathways, we examined the interaction of phosphorylation of Erk1, Erk2, p38 MAPK, JNK1, JNK2/3, and STAT-1. Among these, FGF-2 most strongly phosphorylated Erk1 and Erk2; however, overexpression of cGKII affected none of these in the presence or absence of FGF-2, indicating no apparent interaction between cGKII and FGF, MAPK, or STAT-1 signaling (Supplemental Figure 2A).

Partial reversal of the skeletal abnormality in Prkg2-/- mice by GSK-3 $\beta$ insufficiency. To test whether GSK-3 $\beta$ plays a role in mediating the effect of cGKII-induced skeletal growth changes in vivo, we examined the effect of genetic insufficiency of GSK-3 $\beta$ on the skeletal abnormality apparent in Prkg2 $2^{-/-}$mice. Although $\mathrm{Gsk}_{3} \mathrm{~b}^{-/-}$mice were embryonically lethal (17), Gsk $3 b^{+/-}$mice developed and grew

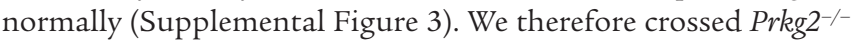

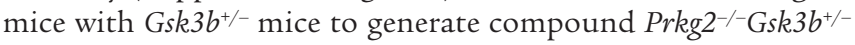
mice. Radiographic analysis and total axial length measurement showed that rrkg $^{-/-} \mathrm{Gsk} 3 \mathrm{~b}^{+/-}$mice exhibited partial, but significant, restoration (about 30\%-40\%) of the impaired skeletal growth of Prkg2 $2^{--}$mice at 8, 12, and 16 weeks after birth (Figure 6, A and B). Measurement of skeletal length confirmed that the endochondral ossification of femur, tibia, humerus, ulna, vertebra, and skull were decreased by cGKII deficiency, while skull width and clavicle length - which are known to develop by endochondral and intra- 
A

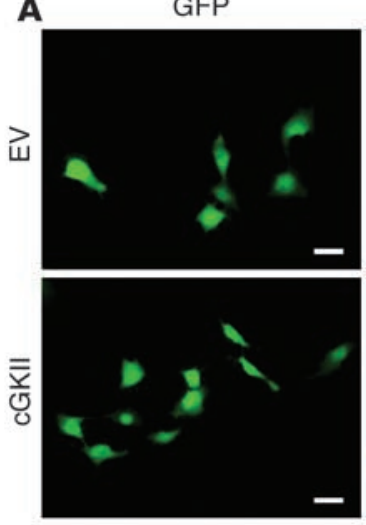

GFP-Sox9
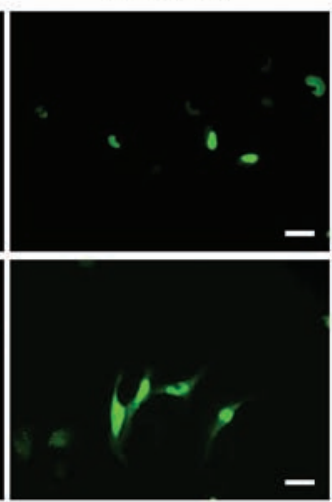

GFP-Sox $9^{\text {S64A }}$
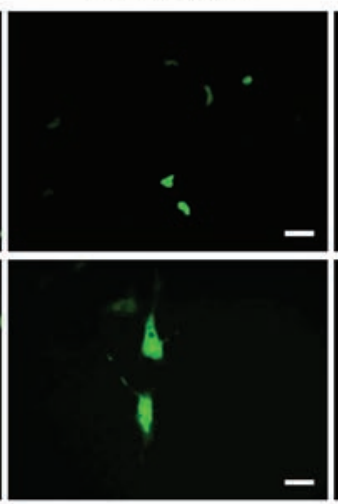

GFP-Sox9 $9^{\text {S181A }}$
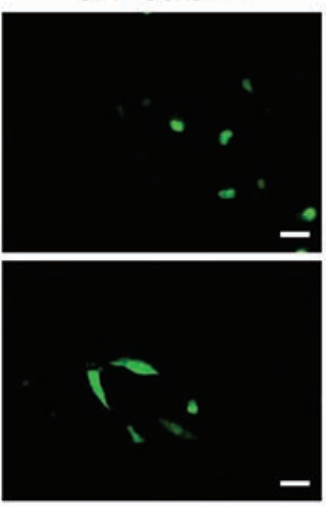

GFP-Sox9 $9^{\mathrm{S} 64 \mathrm{~A}+\mathrm{S} 181 \mathrm{~A}}$

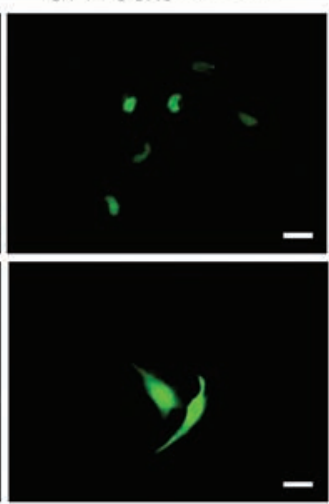

B
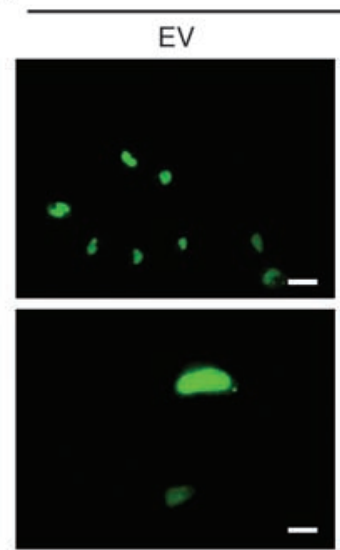

GFP-Sox9
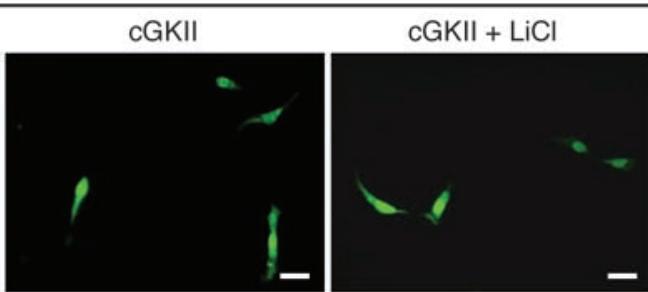

$c G K I I+G S K-3 \beta^{S 9 A}$
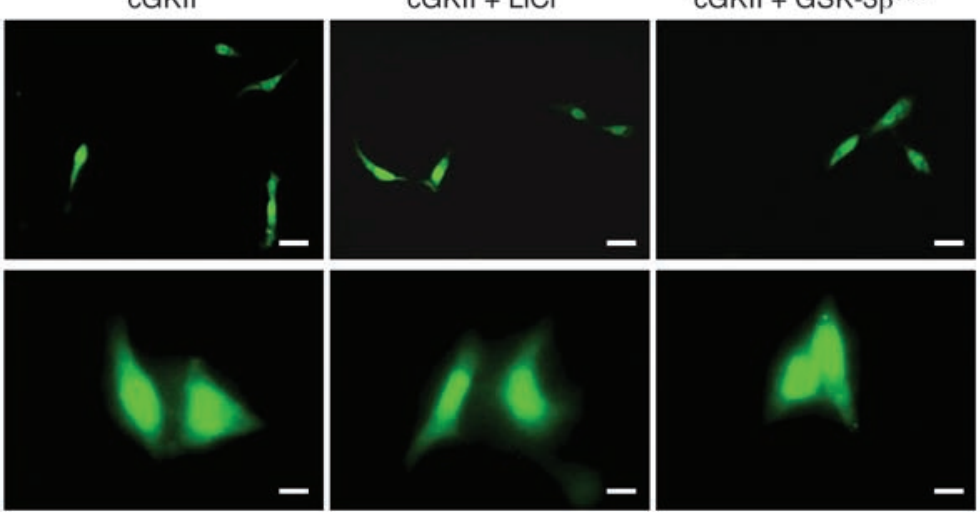

Figure 5

Subcellular localization of Sox9. (A) Effect of cGKII on subcellular localization of Sox9 and the phosphorylation-deficient mutants at putative

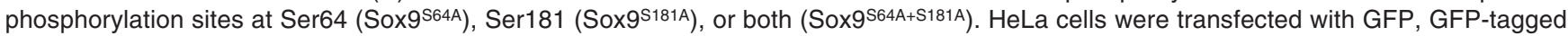
Sox9 (GFP-Sox9), or the GFP-tagged mutants in combination with cGKII or empty vector. Subcellular localization of Sox9 or the mutants was determined by a fluorescent microscope. (B) Effect of LiCl treatment or GSK-3 $\beta^{\mathrm{SgA}}$ transfection on Sox9 subcellular localization in HeLa cells cotransfected with GFP-tagged Sox9 in combination with cGKII or empty vector. Scale bars: $10 \mu \mathrm{m}(\mathbf{A}) ; 20 \mu \mathrm{m}$ (B, top); $5 \mu \mathrm{m}$ (B, bottom).

membranous ossification $(11,18)$ - were comparable to those of WT littermates (Figure 6C). The genetic insufficiency of GSK-3 $\beta$ in the Prkg $2^{-1-} \mathrm{Gsk} 3 \mathrm{~b}^{+/-}$mice partially, but significantly, restored the impaired skeletal growth (about 20\%-40\%). These findings indicate that sufficient GSK-3 $\beta$ function is needed for skeletal growth and endochondral ossification to be impaired by cGKII deficiency.

Further histological analyses revealed that the elongated growth plate and decreased COL10 expression in Prkg2 ${ }^{-/-}$mice were also partially restored in the $\mathrm{Prkg}^{-/-} \mathrm{Gsk} 3 \mathrm{~b}^{+/-}$mice (Figure 7, A and B). In contrast, GSK-3 $\beta$ insufficiency did not alter skeletal growth or growth plate parameters in WT or Prkg2 $2^{+-}$mice, as shown in Gsk $3 b^{+/-}$and compound Prkg2 $2^{+/-}$Gsk $3 b^{+/-}$mice, respectively (Supplemental Figure 3). GSK-3 $\beta$ may therefore function specifically as a mediator of cGKII signaling, rather than generally in the regulation of chondrocyte hypertrophy and endochondral ossification.

\section{Discussion}

Based on our previous finding that cGKII activity is essential for the promotion of skeletal growth through hypertrophic differentiation of growth plate chondrocytes (9), the results of our present study initially identified GSK- $3 \beta$ as a likely substrate of this protein kinase. Figure $7 \mathrm{C}$ summarizes the mechanism underlying chondrocyte hypertrophy by cGKII/GSK-3 $\beta$ signaling based on the present and previous studies. cGKII phosphorylates GSK-3 $\beta$ at Ser9 and inactivates it, which may contribute to the suppression of $\beta$-catenin degradation, as previously reported (10). We and others have reported that $\beta$-catenin/TCF signaling causes stimulation of hypertrophic differentiation of chondrocytes in vitro (19-22). In addition, chondrocyte-specific inactivation of $\beta$-catenin in mice results in dwarfism with delayed hypertrophic differentiation of chondrocytes (23). Hence, the stabilization and accumulation of $\beta$-catenin by cGKII/GSK-3 $\beta$ signaling in chondrocytes may lead to hypertrophic differentiation, although the underlying molecular mechanism is still controversial.

Genetic rescue of impaired skeletal growth in Prkg2 ${ }^{-/-}$mice by suppression of GSK-3 $\beta$ was significant, but incomplete (Figures 6 and 7). This might be because GSK-3 $\beta$ haploinsufficiency was inadequate to fully overcome the deficiency of cGKII. Indeed, cultured $\mathrm{Gsk} 3 \mathrm{~b}^{+/-}$chondrocytes showed higher COL10 expression, but similar ALP and MMP-13 expression, compared with WT cells, while $\mathrm{LiCl}$ clearly increased all hypertrophic markers in the ATDC5 cell culture (Figure 3, A and C). We cannot exclude the possibil- 

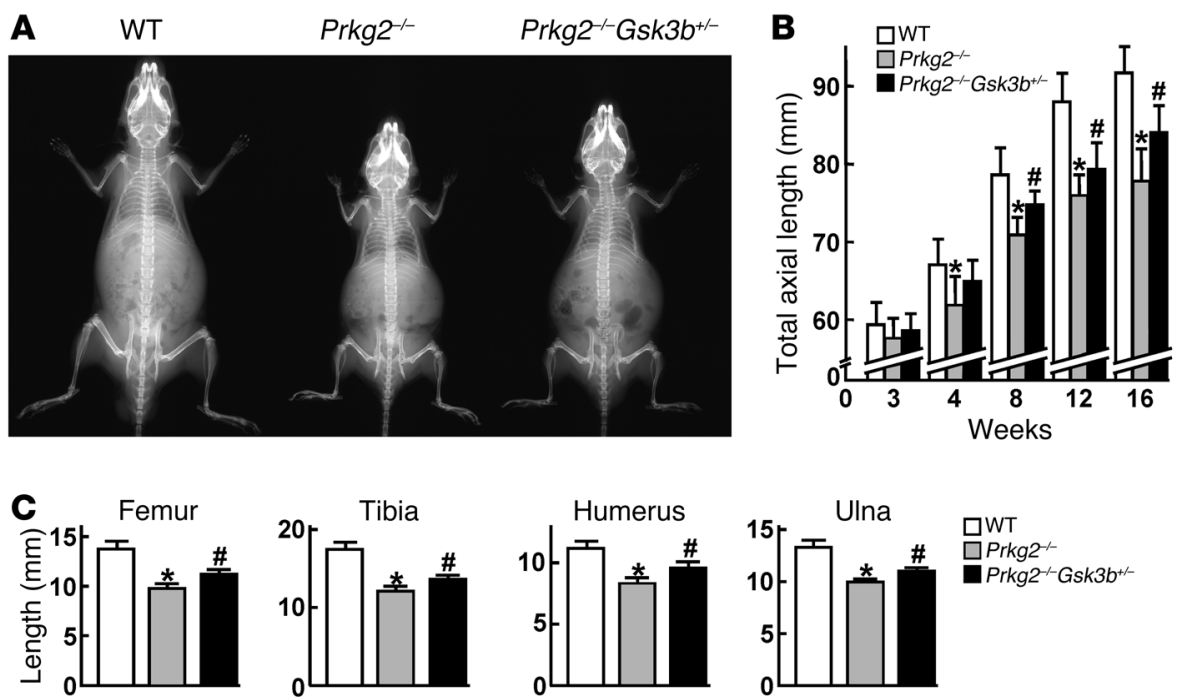

Skull width
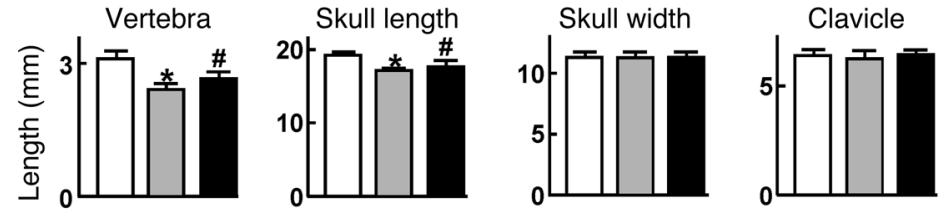

Figure 6

Genetic rescue of growth retardation in Prkg2--- mice by GSK-3 $\beta$ insufficiency. (A) Radiographs of WT, Prkg2-/-, and Prkg2-/Gsk $3 b^{+/-}$littermates at 8 weeks of age. (B) Time course of total axial length (from nose to tail end) of the 3 genotypes from 3 to 16 weeks of age. The recovery by the GSK-3 $\beta$ insufficiency in the Prkg2 ${ }^{-1-}$ mice was $43.2 \%, 31.4 \%$, and $41.9 \%$ at 8,12 , and 16 weeks, respectively. (C) Length of bones of the 3 genotypes at 8 weeks of age. Percent recovery was $21.7 \%, 18.3 \%, 24.3 \%$, $16.2 \%, 24.3 \%$, and $42.6 \%$ in femur, tibia, humerus, ulna, vertebra, and skull length, respectively. Data are mean \pm SD for $4-9$ mice per genotype. ${ }^{*} P<0.05$ versus WT. ${ }^{\#} P<0.05$ versus Prkg2 $^{-1-}$. ity, however, of involvement of other mechanisms in the actions of cGKII on chondrocyte hypertrophy. Although our previous study showed that cGKII phosphorylated Sox9, an inhibitor of chondrocyte hypertrophy, and suppressed its nuclear entry (9), the present study revealed that the subcellular translocation was not mediated by the phosphorylation of Sox9 itself or of GSK-3 $\beta$ (Figure 5). Besides Sox9 and GSK-3 $\beta$, VASP and cysteine- and glycine-rich protein 2 have previously been reported as phosphorylation targets of cGKII in other types of cells (24). However, our luciferase assays failed to show regulation of COL10 transcription by either gene (Figure 2B and Supplemental Figure 2B), suggesting the existence of other phosphorylation targets of cGKII in the regulation of Sox9 translocation associated with chondrocyte hypertrophy. In addition, because Sox 9 has previously been reported to physically interact with $\beta$-catenin and to compete with its binding to TCF (23), the downstream pathways of cGKII through GSK-3 $\beta$ and Sox 9 might interact at the level of $\beta$-catenin during chondrocyte hypertrophy.

Chondrocyte hypertrophy in the growth plate is a rate-limiting step for longitudinal skeletal growth (25), because this step has been shown to be responsible for $40 \%-60 \%$ of endochondral ossification, with the remainder caused by chondrocyte proliferation and matrix synthesis (26). Sox9 is a representative regulator of this step, as are Runx2 $(1,13)$ and parathyroid hormone/parathyroid hormone-related protein $(\mathrm{PTH} / \mathrm{PTHrP})(1,27)$, uncovered via recent advances in molecular genetics. The present study failed to find interaction between cGKII and Runx2 (Supplemental Figure 1). Although PTH/PTHrP has previously been shown to be a potent inhibitor of chondrocyte hypertrophy by the findings in deficient and transgenic mice $(1,27)$, our previous study revealed that neither expression levels of PTHrP and PTH/PTHrP receptor nor cAMP accumulation by PTH stimulation was altered by cGKII deficiency in chondrocytes (9). Hence, cGKII may regulate chondrocyte hypertrophy by a mechanism independent of those of Runx2 and PTH/PTHrP.
In line with the view that cGKII is a downstream mediator of

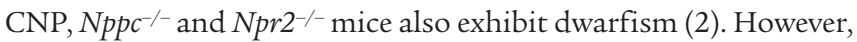
unlike Prkg2-/- mice, which have an elongated growth plate with an abnormal intermediate layer, both $\mathrm{Nppc}^{-/-}$mice and $\mathrm{Npr}^{-{ }^{--}}$mice showed thinned growth plates with chondrocytes arranged in a regular columnar array. This may indicate the involvement of other signaling pathways in CNP/GC-B-mediated endochondral ossification. In fact, the intracellular accumulation of cGMP caused by CNP/GC-B signaling activates not only cGKII, but also other downstream mediators, such as cGKI, cyclic nucleotide phosphodiesterases, and cGMP-regulated ion channels $(5,28)$. Although no skeletal abnormality has been reported in $P r k g 1^{-1-}$ mice (8), it would be helpful to investigate whether mice doubly deficient for cGKI and cGKII mimic the phenotype of $\mathrm{Nppc}^{-/-}$or $\mathrm{Npr}^{-/-}$mice. In addition, targeted overexpression of CNP in growth plate chondrocytes was reported to restore the achondroplastic bone with FGF receptor 3 mutation through inhibition of the MAPK pathway (15), which we found in the present study to be unrelated to cGKII (Supplemental Figure 2A). Furthermore, cGKII functions as an effector of cGMP that is activated not only by CNP, but also by nitric oxide and other types of natriuretic peptides $(5,7,28)$. Although the fact that CNP was unable to affect chondrocyte differentiation of skeletal growth in the absence of cGKII either in vitro or in vivo indicates a crucial role of cGKII in CNP signaling (29), CNP and cGKII are unlikely to function with a one-to-one correspondence during endochondral ossification.

The abnormal elongation of the Prkg2-/- mouse growth plate was apparent from 2 to 4 weeks after birth, but not before or after these ages (Figure 1B). This observation suggests some compensatory mechanisms for cGKII deficiency. Besides signaling via Runx2, PTH/PTHrP, and the CNP-related factors described above, GSK- $3 \alpha$ (the other GSK-3 in mammals) might substitute for GSK-3 $\beta$, because it was not found to be a phosphorylation target of cGKII (Figure 2D). Although there was no compensatory upregulation in 
A
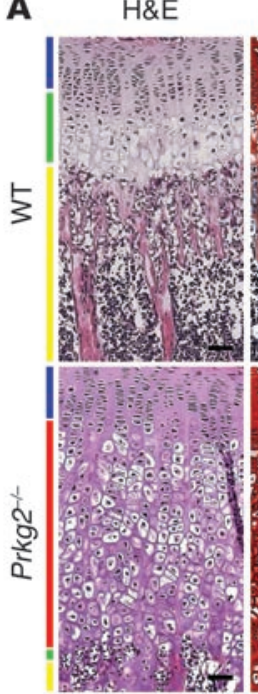

Safranin-O
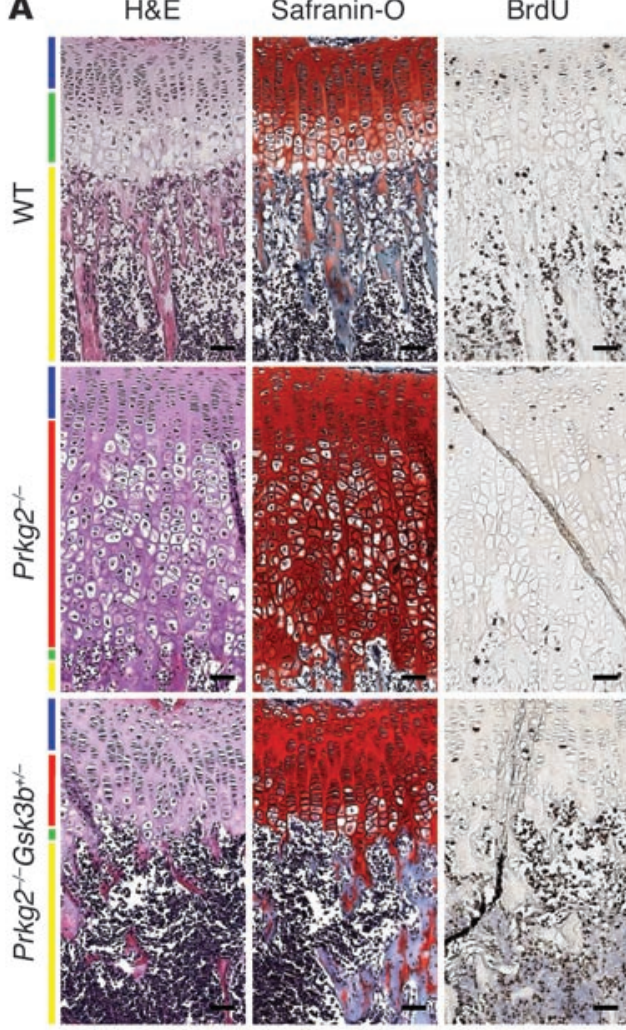

B

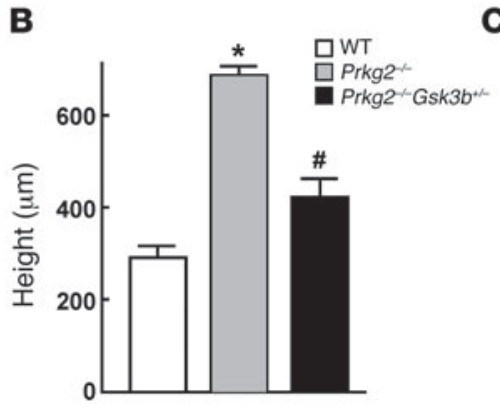

COL10
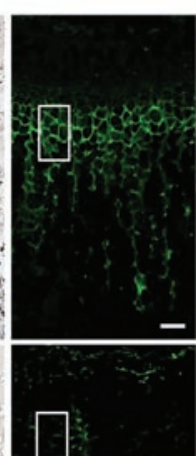

COL10
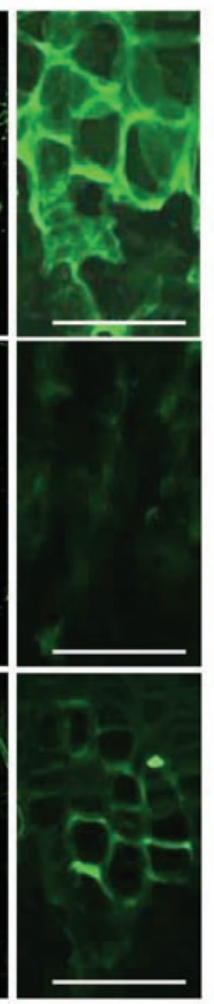

C

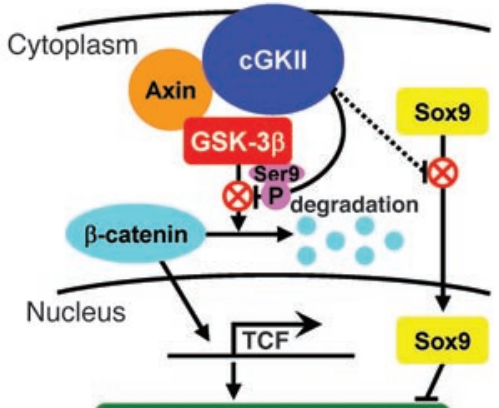

Chondrocyte hypertrophy
GSK-3 levels in cells lacking either GSK-3 $\alpha$ or GSK-3 $\beta$, functional redundancy of the 2 GSK- 3 homologs in $\beta$-catenin/TCF-mediated transcription was previously shown using an allelic series of embryonic stem cell lines $(17,30)$. In fact, Gsk3b $b^{+/-}$mice (Supplemental Figure 3) and Gsk3 $3 a^{-1-}$ mice (31) showed normal skeletal development and growth. Gsk $3 b^{-/-}$mice developed relatively normally until late gestation, when massive liver apoptosis causes embryonic lethality (17); the implication of this finding is that GSK-3 $\alpha$ can compensate for GSK-3 $\beta$ deficiency in early stages of mouse development, but cannot substitute for it in all respects. Hence, the age-dependent balance between GSK-3 $\alpha$ and GSK-3 $\beta$ might explain the temporary growth plate abnormality in Prkg2 ${ }^{-/}$mice.

GSK-3 $\beta$ is known to be active under resting conditions and inactivated upon stimulation by several signaling pathways, such as Wnt and insulin/Akt; however, the role of phosphorylation of GSK-3 $\beta$ remains controversial $(32,33)$. Our present results led us to propose cGKII as a novel regulator of GSK-3 $\beta$ and showed that the $\beta$-catenin activity enhanced by cGKII was suppressed by

\section{Figure 7}

Genetic rescue of growth plate abnormality in $\mathrm{Prkg}^{-/-}$ mice by GSK-3 $\beta$ insufficiency. (A) H\&E staining, Safranin-O staining, BrdU labeling, and immunohistochemical staining of COL10 in the tibial growth plates of 3-weekold mice of the 3 genotypes. Blue, red, green, and yellow bars indicate proliferative zone, abnormal intermediate layer, hypertrophic zone, and primary spongiosa, respectively. Boxed regions in COL10 panels are shown at higher magnification to the right. Scale bars: $50 \mu \mathrm{m}$. (B) Height of the growth plates of the 3 genotypes. The percentage recovery by the GSK-3 $\beta$ insufficiency was $36.0 \%$. Data are mean \pm SD of 4 mice per genotype. ${ }^{*} P<0.05$ versus WT. ${ }^{*} P<0.05$ versus $P$ rkg2 ${ }^{-1-}$. (C) Schematic of the mechanism whereby cGKII promotes growth plate chondrocyte hypertrophy during skeletal growth.

GSK- $3 \beta^{\mathrm{S} 9 \mathrm{~A}}$, indicating the mediation of GSK-3 $\beta$ phosphorylation at Ser9 in cGKII/ $\beta$-catenin signaling (Figure 4C). Conversely, several reports showed that GSK-3 $\beta$ inactivation causing $\beta$-catenin induction by Wnt stimulation depends not on Ser9 phosphorylation, but rather on coupling with the scaffolding protein, such as Axin $(34,35)$. The present study, however, showed that cGKII formed a complex with Axin and further phosphorylated GSK-3 $\beta$ that bound to Axin (Figure 4D), suggesting some interaction between Ser9 phosphorylation and coupling with Axin in the regulation of GSK-3 $\beta$ by cGKII. In fact, a previous report proposed that Wnt signaling, similar to insulin/Akt signaling, induces GSK-3 $\beta$ phosphorylation via the interaction between the signaling pathways both in neuronal PC12 cells and in human embryonic kidney 293 T cells (36). While these findings imply a possible link between cGKII/ $\beta$-catenin and canonical Wnt $/ \beta$-catenin signaling, we note that there is no direct evidence of cGKII being involved in the canonical Wnt pathway. We therefore believe that cGKII $/ \beta$-catenin signaling, which is dependent on GSK-3 $\beta$ phosphorylation, may have a mechanism that is, at least in part, distinct from that of Wnt/ $\beta$-catenin signaling. Further studies will be needed to clarify the details of GSK-3 $\beta$-related signaling not only in chondrocytes, but also in other cells.

We conclude that cGKII promotes chondrocyte hypertrophy and skeletal growth through phosphorylation and inactivation of GSK-3 $\beta$. For the application of this intracellular signaling to yield novel therapeutics for skeletal disorders, we are now developing a gene transfer system using biocompatible polyplex nanomicelles (37, 38). Further understanding of the molecular signaling related to the cGKII/GSK-3 $\beta$ axis, in combination with other putative signaling systems, will greatly assist in unraveling the molecular network that modulates endochondral ossification and skeletal growth.

\section{Methods}

Animals. The Prkg2-/- mice and Gsk36 ${ }^{+/-}$mice were maintained in a C57BL/6

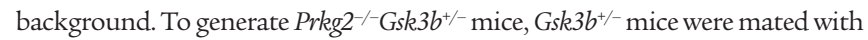
the homozygous $\mathrm{Prkg}^{2--}$ mice to obtain $\mathrm{Prkg}^{+/-} \mathrm{Gsk}_{3} \mathrm{~b}^{+/-}$mice, which were then mated with each other. All experiments were performed on male mice and were approved by the Animal Care and Use Committee of the University of Tokyo. 
Radiological and histological analyses. Plain radiographs were taken using a soft X-ray apparatus (Softex CMB-2; Softex). For histological analyses, skeletons were fixed in $4 \%$ paraformaldehyde, decalcified with $10 \%$ EDTA, embedded in paraffin, sectioned in $5-\mu \mathrm{m}$ slices, and stained with $\mathrm{H} \& \mathrm{E}$ or Safranin-O, according to standard procedures. For BrdU labeling, mice were injected intraperitoneally with $\mathrm{BrdU}(25 \mu \mathrm{g} / \mathrm{g}$ body weight $)$ $2 \mathrm{~h}$ prior to sacrifice, and the sections were stained with a BrdU staining kit (Zymed Laboratories) according to the manufacturer's instructions. In situ hybridization with nonradioactive probes was performed as previously described (39). For immunohistochemistry, antibodies to cGKII, Ser9-phosphorylated GSK-3 $\beta$, MMP-13, Runx2 (1:50; Santa Cruz Biotechnology Inc.), GSK-3 $\beta$ (1:200; Chemicon), COL10 (1:1000; LSL), $\beta$-catenin (1:100; Cell Signaling Technology), and respective nonimmune serums were used, and the signal was detected with an HRP-conjugated secondary antibody. For fluorescent visualization, a secondary antibody conjugated with Alexa Fluor 488 (Invitrogen) was used.

Cell cultures. ATDC5 cells were grown and maintained in DMEM and F12 at a 1:1 ratio with 5\% FBS. To induce hypertrophic differentiation, the ATDC5 cells were cultured in the presence of insulin, transferrin and sodium selenite (ITS) supplement (Sigma-Aldrich) for $21 \mathrm{~d}$ as described previously (40). We confirmed COL10 expression by real-time RT-PCR and used the cells whose stage of differentiation was assumed to be prehypertrophic or hypertrophic. Primary chondrocytes were isolated by digestion of E18.5 costal cartilage. Primary chondrocytes, HuH-7 cells, HEK293 cells, and HeLa cells were cultured in high-glucose DMEM with $10 \%$ FBS. Threedimensional alginate bead cultures of primary costal chondrocytes and ATDC5 cells were performed with or without $\mathrm{LiCl}(8 \mathrm{mM})$ for $72 \mathrm{~h}$, and the cells were analyzed as described previously (21). For immunocytochemistry of primary costal chondrocytes, the cell colonies were fixed with $4 \%$ paraformaldehyde, embedded in paraffin, sectioned in 5 - $\mu \mathrm{m}$ slices, and underwent immunostaining for COL10 and MMP-13 as described above. For ALP staining, sections were fixed in 70\% ethanol and stained for $10 \mathrm{~min}$ with a solution containing $0.01 \%$ Naphthol AS-MX phosphate disodium salt (Sigma-Aldrich), 1\% N, N-dimethyl-formamide (Wako Pure Chemical Industries Ltd.), and $0.06 \%$ fast blue BB (Sigma-Aldrich).

In vitro kinase assay. ATDC5 cells were cultured in the presence of ITS for $21 \mathrm{~d}$ to differentiate into prehypertrophic or hypertrophic chondrocytes, as described above. The whole-cell lysate of the differentiated cells was prepared using Cell Lysis Buffer (Cell Signaling Technology). The cell lysate or recombinant GSK-3 $\beta$ (Upstate Biotechnology Inc.) was incubated with recombinant cGKII (Sigma-Aldrich) in a reaction buffer (Cell Signaling Technology) containing $1.6 \mathrm{mM}$ ATP and $100 \mu \mathrm{M}$ 8-bromo-cGMP (Bio$\mathrm{mol})$ at $30^{\circ} \mathrm{C}$ for $30 \mathrm{~min}$. An equal amount of protein $(15 \mu \mathrm{g})$ was subjected to SDS-PAGE and transferred onto nitrocellulose membranes. IB was then performed using primary antibodies to Ser9-phosphorylated GSK-3 $\beta$ (Cell Signaling Technology), GSK-3 $\beta$ (Chemicon), Ser21-phosphorylated GSK- $3 \alpha$ and GSK- $3 \alpha$ (Cell Signaling Technology), and $\beta$-actin (SigmaAldrich). The membrane was incubated with HRP-conjugated antibody (Promega), and the immunoreactive proteins were visualized with ECL Plus (Amersham Biosciences).

Plasmids and viral vectors. cDNA of caspase-9 (GenBank accession no. NM_001229.1), Bad (NM_007522.2), PLK (NM_011121.3), p90RSK (NM_009097.4), eNOS (NM_000603.3), GSK-3ß (NM_002093.2), VASP (NM_009499.1), cdc25 (NM_009860.2), and cysteine- and glycine-rich protein 2 (CSRP2; NM_007792.3) was ligated into pCMV-HA (Invitrogen). cDNA of rat cGKII (NM_013012.1; nucleotides 48-2,333) was ligated into pcDNA4HisA (Invitrogen). A PCR-amplified fragment (nucleotides 48-1,403) was used to construct the cGKII- $\Delta$ kinase plasmid. Plasmids encoding constitutively active human cGKII were kindly provided by B.M. Hogema (Erasmus University Medical Center, Rotterdam,
The Netherlands; ref. 41). Axin1 (NM_003502.2) was subcloned into pCMV-Myc (Invitrogen) to introduce Myc epitope tags. cDNA of Sox 9 (NM_000346.2) and Runx2 (NM_009820.3) was ligated into pEGFPC1 (Clontech) to generate GFP-tagged plasmids. To create phosphorylation-deficient mutants, GFP-tagged Sox 9 plasmid and GSK-3 $\beta$ plasmid were subjected to site-directed mutagenesis using the inverse PCR technique. All constructs were verified by sequencing. cGKII, cGKII- $\Delta$ kinase, GSK- $3 \beta^{\mathrm{S} 9 \mathrm{~A}}$, and control GFP retrovirus vectors were constructed using $\mathrm{pMx}$ vector and plat-E cells as described previously (42).

Gene transfection. For the transient transfection, a total of $1 \mu \mathrm{g}$ plasmid DNA was transfected using Fugene6 (Roche). For cotransfection, all plasmids were added in an equal ratio. Total RNA was isolated $72 \mathrm{~h}$ after the transfection and used for the subsequent assays. For fluorescent detection, HeLa cells were transiently transfected, and fluorescent images were taken $24 \mathrm{~h}$ after transfection. To investigate the interaction of cGKII and MAPK/STAT signaling, ATDC5 cells were transfected with cGKII or the empty vector, and FGF-2 $(1 \mathrm{ng} / \mathrm{ml})$ was added $72 \mathrm{~h}$ after transfection. IB was then carried out using primary antibodies to p-Erk1/2, Erk1/2, p-p38MAPK, p38MAPK, p-JNK2/3, JNK2/3, p-JNK1, JNK1, p-STAT1, and STAT1 (Cell Signaling Technology) as described above.

Real-time RT-PCR. Total RNA was reverse-transcribed with MultiScribe RT (Applied Biosystems Inc.). Semiquantitative RT-PCR was performed within an exponential phase of the amplification, with the following primer sequences: caspase-9 forward, 5'-CGATGCAGGGTGCGCCTAGTGA-3'; caspase-9 reverse, 5'-TGACCAGCTGCCTGGCCTGATC-3'; Bad forward, 5'-CCAGGTCTCCTGGGGAGCAACATTC-3'; Bad reverse, 5'-AGCTCCTCCTCCATCCСТTCATCC-3'; PLK forward, 5'-TGGCACTCCTAACTACATAGCTCCTGAGG-3'; PLK reverse, 5'-CGGAGGTAGGTCTCTTTTAGGCACGA-3'; p90RSK forward, 5'-GATTCTTCTGCGGTATGGCCA-3'; p90RSK reverse, 5'-TGCCGTAGGATCTTATCCAGCA-3'; eNOS forward, 5'-CTCGAGTGGTTTGCTGCCCTTG-3'; eNOS reverse, 5'-CAGGTCCCTCATGCCAATCTCTGA-3'; GSK-3 $\beta$ forward, $5^{\prime}$-CCAGTATAGATGTATGGTCTG-3'; GSK- $3 \beta$ reverse, 5'-CTTGTTGGTGTTCCTAGG-3'; VASP forward, 5'-TTCCAGCCGGGCTACTGTGATG-3'; VASP reverse, 5'-CGGCCAACAACTCGGAAGGAGT-3'; cdc25 forward, 5'-GCACTGGAAAGGGTGGAGAGACTGG-3'; cdc25 reverse, 5'-CCTCTTCACTTGCAGGTGGGATAGG-3'; Runx2 forward, 5'-CCCAGCCACCTTTACCTACA-3'; Runx2 reverse, 5'-TATGGAGTGCTGCTGGTCTG-3'. Real-time RT-PCR was performed on an ABI 7700 Sequence Detection system (Applied Biosystems) using QuantiTect SYBR Green PCR Master Mix (Qiagen) with $\beta$-actin as the internal control and the following primer sequences: COL10 forward, $5^{\prime}$-CATAAAGGGCCCACTTGCTA-3'; COL10 reverse, 5'-TGGCTGATATTCCTGGTGGT-3'; ALP forward, 5'-GCTGATCATTCCCACGTTTT-3'; ALP reverse, 5'-CTGGGCCTGGTAGTTGTTGT-3'; MMP-13 forward, 5'-AGGCCTTCAGAAAAGCCTTC-3'; MMP-13 reverse, 5'-TCCTTGGAGTGATCCAGACC-3'; $\beta$-actin forward, 5 '-AGATGTGGATCAGCAAGCAG-3'; $\beta$-actin reverse, $5^{\prime}$-GCGCAAGTTAGGTTTTGTCA-3'. All reactions were run in triplicate.

Luciferase reporter gene assay. The human COL10 promoter regions from $-4,459 \mathrm{bp}$ relative to the transcriptional start site were cloned into the pGL3-Basic vector (Promega). The TOPflash system (Upstate Biotechnology Inc.) was used according to the manufacturer's protocol. The luciferase assay was performed with a dual-luciferase reporter assay system (Promega) using a GloMax 96 Microplate Luminometer (Promega).

$I P$ and IB assay. IP was performed with ProFound Myc Tag IP/Co-IP kits (Pierce) according to the manufacturer's protocol. Samples were prepared using M-PER or NE-PER (Pierce) supplemented with $2 \mathrm{mM} \mathrm{Na}_{3} \mathrm{VO}_{4}$ and $10 \mathrm{mM} \mathrm{NaF}$ according to the manufacturer's protocol. Cell lysates were incubated with the high-affinity anti-c-Myc antibody-coupled agarose 
at $4^{\circ} \mathrm{C}$ overnight. Immunocomplexes were washed 3 times with cold wash solution. c-Myc-tagged proteins were eluted, and an equal amount of each eluted sample $(15 \mu \mathrm{g})$ was subjected to SDS-PAGE, transferred onto nitrocellulose membranes, and subjected to IB using primary antibodies to cGKII (Santa Cruz Biotechnology Inc.), GSK-3 $\beta$ and Ser9phosphorylated GSK-3 $\beta$ (Chemicon), and Myc tag (Upstate Biotechnology Inc.). Immunoreactive proteins were visualized as described above.

Statistics. Means of groups were compared by ANOVA, and significance of differences was determined by post-hoc testing by the Bonferroni method. A $P$ value less than 0.05 was considered significant.

\section{Acknowledgments}

We thank Boris M. Hogema for providing plasmids encoding constitutively active human cGKII; Henry Kronenberg and
Sakae Tanaka for critical discussions; and Reiko Yamaguchi and Mizue Ikeuchi for their excellent technical help. This work was supported by Grant-in-Aid no. 14657359 for Scientific Research from the Japanese Ministry of Education, Culture, Sports, Science and Technology.

Received for publication February 5, 2008, and accepted in revised form May 7, 2008.

Address correspondence to: Hiroshi Kawaguchi, Sensory and Motor System Medicine, Faculty of Medicine, University of Tokyo, Hongo 7-3-1, Bunkyo-ku, Tokyo 113-8655, Japan. Phone: 81-33815-5411 ext. 30473; Fax: 81-33818-4082; E-mail: kawaguchi-ort@h.u-tokyo.ac.jp.
1. Kronenberg, H.M. 2003. Developmental regulation of the growth plate. Nature. 423:332-336.

2. Chusho, H., et al. 2001. Dwarfism and early death in mice lacking C-type natriuretic peptide. Proc. Natl. Acad. Sci. U. S. A. 98:4016-4021.

3. Tamura, N., et al. 2004. Critical roles of the guanylyl cyclase B receptor in endochondral ossification and development of female reproductive organs. Proc. Natl. Acad. Sci. U. S. A. 101:17300-17305.

4. Bartels, C.F., et al. 2004. Mutations in the transmembrane natriuretic peptide receptor NPR-B impair skeletal growth and cause acromesomelic dysplasia, type Maroteaux. Am. J. Hum. Genet. 75:27-34.

5. Schulz, S. 2005. C-type natriuretic peptide and guanylyl cyclase B receptor. Peptides. 26:1024-1034.

6. Pfeifer, A., et al. 1996. Intestinal secretory defects and dwarfism in mice lacking cGMP-dependent protein kinase II. Science. 274:2082-2086.

7. Pfeifer, A., et al. 1999. Structure and function of cGMP-dependent protein kinases. Rev. Physiol. Biochem. Pharmacol. 135:105-149.

8. Pfeifer, A., et al. 1998. Defective smooth muscle regulation in cGMP kinase I-deficient mice. EMBO J. 17:3045-3051.

9. Chikuda, H., et al. 2004. Cyclic GMP-dependent protein kinase II is a molecular switch from proliferation to hypertrophic differentiation of chondrocytes. Genes Dev. 18:2418-2429.

10. Doble, B.W., and Woodgett, J.R. 2003. GSK-3: tricks of the trade for a multi-tasking kinase. J. Cell Sci. 116:1175-1186.

11. Holmbeck, K. 2005. Collagenase in cranial morphogenesis. Cells Tissues Organs. 181:154-165.

12. Akiyama, H., Chaboissier, M.C., Martin, J.F., Schedl, A., and de Crombrugghe, B. 2002. The transcription factor Sox 9 has essential roles in successive steps of the chondrocyte differentiation pathway and is required for expression of Sox 5 and Sox6. Genes Dev. 16:2813-2828.

13. Takeda, S., Bonnamy, J.P., Owen, M.J., Ducy, P., and Karsenty, G. 2001. Continuous expression of Cbfa1 in nonhypertrophic chondrocytes uncovers its ability to induce hypertrophic chondrocyte differentiation and partially rescues Cbfa1-deficient mice. Genes Dev. 15:467-481.

14. Ornitz, D.M. 2005. FGF signaling in the developing endochondral skeleton. Cytokine Growth Factor Rev. 16:205-213.
15. Yasoda, A., et al. 2004. Overexpression of CNP in chondrocytes rescues achondroplasia through a MAPK-dependent pathway. Nat. Med. 10:80-86.

16. Deng, C., Wynshaw-Boris, A., Zhou, F., Kuo, A., and Leder, P. 1996. Fibroblast growth factor receptor 3 is a negative regulator of bone growth. Cell. 84:911-921.

17. Hoeflich, K.P., et al. 2000. Requirement for glycogen synthase kinase-3beta in cell survival and NF-kappaB activation. Nature. 406:86-90.

18. Huang, L.F., Fukai, N., Selby, P.B., Olsen, B.R., and Mundlos, S. 1997. Mouse clavicular development: analysis of wild-type and cleidocranial dysplasia mutant mice. Dev. Dyn. 210:33-40.

19. Dong, Y.F., Soung do, Y., Schwarz, E.M., O’Keefe, R.J., and Drissi, H. 2006. Wnt induction of chondrocyte hypertrophy through the Runx2 transcription factor. J. Cell Physiol. 208:77-86.

20. Hartmann, C., and Tabin, C.J. 2000. Dual roles of Wnt signaling during chondrogenesis in the chicken limb. Development. 127:3141-3159.

21. Yano, F., et al. 2005. The canonical Wnt signaling pathway promotes chondrocyte differentiation in a Sox9-dependent manner. Biochem. Biophys. Res. Commun. 333:1300-1308.

22. Tamamura, Y., et al. 2005. Developmental regulation of Wnt/beta-catenin signals is required for growth plate assembly, cartilage integrity, and endochondral ossification. J. Biol. Chem. 280:19185-19195.

23. Akiyama, H., et al. 2004. Interactions between Sox9 and beta-catenin control chondrocyte differentiation. Genes Dev. 18:1072-1087.

24. Schlossmann, J., and Hofmann, F. 2005. cGMPdependent protein kinases in drug discovery. Drug Discov. Today. 10:627-634.

25. Hunziker, E.B. 1994. Mechanism of longitudinal bone growth and its regulation by growth plate chondrocytes. Microsc. Res. Tech. 28:505-519.

26. Wilsman, N.J., Farnum, C.E., Leiferman, E.M., Fry, M., and Barreto, C. 1996. Differential growth by growth plates as a function of multiple parameters of chondrocytic kinetics. J. Orthop. Res. 14:927-936.

27. Kronenberg, H.M. 2006. PTHrP and skeletal development. Ann. N. Y. Acad. Sci. 1068:1-13.

28. Pilz, R.B., and Casteel, D.E. 2003. Regulation of gene expression by cyclic GMP. Circ. Res. 93:1034-1046.

29. Miyazawa, T., et al. 2002. Cyclic GMP-dependent protein kinase II plays a critical role in C-type natri- uretic peptide-mediated endochondral ossification. Endocrinology. 143:3604-3610.

30. Doble, B.W., Patel, S., Wood, G.A., Kockeritz, L.K., and Woodgett, J.R. 2007. Functional redundancy of GSK-3alpha and GSK-3beta in Wnt/beta-catenin signaling shown by using an allelic series of embryonic stem cell lines. Dev. Cell. 12:957-971.

31. MacAulay, K., et al. 2007. Glycogen synthase kinase 3alpha-specific regulation of murine hepatic glycogen metabolism. Cell Metab. 6:329-337.

32. Patel, S., Doble, B., and Woodgett, J.R. 2004. Glycogen synthase kinase- 3 in insulin and Wnt signalling: a double-edged sword? Biochem. Soc. Trans. 32:803-808.

33. Dominguez, I., and Green, J.B. 2001. Missing links in GSK3 regulation. Dev. Biol. 235:303-313.

34. Papadopoulou, D., Bianchi, M.W., and Bourouis, M. 2004. Functional studies of shaggy/glycogen synthase kinase 3 phosphorylation sites in Drosophila melanogaster. Mol. Cell. Biol. 24:4909-4919.

35. Ding, V.W., Chen, R.H., and McCormick, F. 2000. Differential regulation of glycogen synthase kinase 3 beta by insulin and Wnt signaling. J. Biol. Chem. 275:32475-32481.

36. Fukumoto, S., et al. 2001. Akt participation in the Wnt signaling pathway through Dishevelled. J. Biol. Chem. 276:17479-17483.

37. Itaka, K., et al. 2007. Bone regeneration by regulated in vivo gene transfer using biocompatible polyplex nanomicelles. Mol. Ther. 15:1655-1662.

38. Ohba, S., et al. 2007. Identification of a potent combination of osteogenic genes for bone regeneration using embryonic stem (ES) cell-based sensor. FASEB J. 21:1777-1787.

39. Kamekura, S., et al. 2006. Contribution of runtrelated transcription factor 2 to the pathogenesis of osteoarthritis in mice after induction of knee joint instability. Arthritis Rheum. 54:2462-2470.

40. Shukunami, C., et al. 1997. Cellular hypertrophy and calcification of embryonal carcinoma-derived chondrogenic cell line ATDC5 in vitro. J. Bone Miner. Res. 12:1174-1188.

41. Vaandrager, A.B., et al. 2003. Autophosphorylation of cGMP-dependent protein kinase type II. J. Biol. Chem. 278:28651-28658.

42. Saito, T., Ikeda, T., Nakamura, K., Chung, U.I., and Kawaguchi, H. 2007. S100A1 and S100B, transcriptional targets of SOX trio, inhibit terminal differentiation of chondrocytes. EMBO Rep. 8:504-509. 